\title{
Evolution of Post-Surgical Scars Treated with Pure Rosehip Seed Oil
}

\author{
Pedro Valerón-Almazán'1, Anselmo J. Gómez-Duaso', Néstor Santana-Molina1, \\ Miguel A. García-Bello², Gregorio Carretero' ${ }^{1}$ \\ ${ }^{1}$ Dermatology Service, Hospital Universitario de Gran Canaria Dr. Negrin, Las Palmas, Spain \\ ${ }^{2}$ Research Unit, Hospital Universitario de Gran Canaria Dr. Negrin, Las Palmas, Spain \\ Email: maria.matabuena@invitrotecnia.com
}

Received 28 May 2015; accepted 26 June 2015; published 29 June 2015

Copyright (C) 2015 by authors and Scientific Research Publishing Inc.

This work is licensed under the Creative Commons Attribution International License (CC BY). http://creativecommons.org/licenses/by/4.0/

cC) (i) Open Access

\begin{abstract}
The rosehip seed oil (RHO), obtained from different plant species of the genus Rosa, is one of the compounds used empirically for cosmetic improvement of skin scarring. Despite its widespread use in clinical practice, there are few studies evaluating the activity of this compound on the clinical course of cutaneous scars. The aim of this study was to determine the effect of Repavar ${ }^{\circledR}$ rosehip oil on improvement of post-surgical skin scars. One comparative, single-center, prospective clinical trial was carried out in $\mathbf{1 0 8}$ patients undergoing cutaneous surgery procedures in the Dermatology Service of University Hospital of Gran Canaria Dr. Negrín (Spain). Subjective parameters (erythema, discoloration, atrophy and hypertrophy) were evaluated at 6 and 12 weeks on 76 adults who treated scars with pure RHO twice a day (test group), 32 patients with not treatment (control group), and completed the study. Lesser degree of erythema was observed at 6 and 12 weeks in treated-patients compared with the control group and decreased discoloration and atrophy at 12 weeks, with statistically significant differences in all cases $(p<0.05)$. This study demonstrates that the RHO Repavar ${ }^{\circledR}$ is useful for cosmetic improvement on erythema, discoloration and atrophyof post-surgical skin scars, getting a better overall evolution and appearance thereof.
\end{abstract}

\section{Keywords}

Healing, Skin Scar, Rosa Mosqueta, Rosehip Seed Oil, Skin Surgery

\section{Introduction}

Healing is a natural and dynamic process in which body has to regenerate tissues after injury. This process develops along three phases, comprising inflammation, granulation tissue formation and maturation/remodeling [1]-[3]. In the inflammatory phase, platelet degranulation, cell-recruitment migration, and extracellular matrix 
formation are initiated, all mediated by multiple cytokines and growth factors [4]. The proliferative phase starts several days after the initial injury, and it is characterized by angiogenesis, collagen deposition, formation of granulation tissue and epithelialization and contraction of the scar [5]. In the remodeling phase, tissue enzymes remove excess of extracellular matrix and collagen, and remained fibrils are realigned along the tension lines. This remodeling process occurs during 6 - 12 months but may persist for years after initial injury [3].

Clinically, cutaneous scars are defined as macroscopic alterations of the architectural structure of the skin, as a final result of the healing process. The affected area may be displayed as an elevated or depressed area, which has also variations in consistency, color, vascularization and/or innervation. Although many therapies have been tried to improve the clinical appearance of skin scars, no treatment has clearly shown its efficacy and still considers prevention as the most important attitude to avoid the appearance of hypertrophic scars or keloids [6].

"Rosa mosqueta" or "Rosehip", is a generic name which covers about 70 different species of plants of the genus Rosa, as Rosa rubiginosa, Rosa moschata and Rosa canina [7]. The rosehip seed oil (RHO) is extracted from the seed of the fruit of the wild plant. Some studies have examined before the chemical composition of this compound, where the high content of polyunsaturated fatty acid highlights: linoleic acid (54\%), linolenic acid (17\%) and oleic acid (16\%) between others [8]. Lesser amounts of other saturated fatty acids and small amounts of other dermatological active interest like transretinoic acid or natural tretinoin (between $0.01 \%$ and $0.1 \%$ ) have also been identified [9].

In the medical field, the RHO has been used for decades to treat wounds and/or scars. The beneficial effect of this oil has been attributed to its high content of essential fatty and unsaturated acids abovementioned, which play a key role in the permeability of cell membranes and injuries repair mechanisms [10]. Despite its theoretical utility in these processes, there are few studies that evaluate the activity of this compound on the clinical course of healing [11] [12].

The aim of this study was to analyze the clinical course of post-surgical cutaneous scars treated with pure RHO in terms of erythema, discoloration, atrophy and hypertrophy.

\section{Methods}

\subsection{Patients}

108 patients were underwent open surgical procedures for skin tumor removal of pigmented lesions between April and June (over three months), in the Dermatology Service, University Hospital of Gran Canaria Dr. Negrín, were enrolled in a comparative, single-center and prospective study.

Inclusion criteria in the study were elderly patients with sufficient level of understanding, with not-knownRHO-allergies, without any history of keloids or other healing defects.

The Clinical Research Ethics Committee of the Hospital approved the study, and all patients gave informed consent form to participate in it.

\subsection{Treatment}

Patients in the test group had to apply the RHO (Repavar ${ }^{\circledR}$ ) twice a day on the scar, from the removal of sutures, for six weeks. Patients considered as controls did not perform any treatment.

Patients were assigned to each group randomly and the same experienced dermatologist performed the evaluation in all groups of patients, so that all observations follow the same validated criteria.

\subsection{Analysis Parameters}

The variables were analyzed at 6 and 12 weeks after removal of sutures, and data were recorded taking into account this classification (Table 1 ):

Table 1. Evaluation criteria of parameters erythema, discoloration, atrophy and hypertrophy.

\begin{tabular}{rccccccrrr}
\hline & Erythema & \multicolumn{3}{c}{ Dyschromia } & & Atrophy & Hypertrophy \\
\hline 0 & No erythema & 0 & No color change & 0 & No atrophy & 0 & No hypertrophy \\
1 & Mild (pink) & 1 & Slight hyper/hypochromia & 1 & Slight depression & 1 & Slight hypertrophy \\
2 & Intense (red) & 2 & Major hyper/hypochromia & 2 & Major depression & 2 & Major hypertrophy (keloid)
\end{tabular}


For the descriptive analysis, categorical variables were expressed as absolute frequencies and percentages.

\subsection{Statistical Analysis}

For statistical analysis, the Chi-square test was used, considering a level of statistical significance $\alpha<0.05$.

\section{Results and Discussion}

A total of 160 patients were included in the trial, of whom 120 patients were treated with RHO and 40 underwent no treatment (control).

103 patients from the 120 treated patients group attended the review of 6 weeks and 76 attended the review of the 12 weeks. 32 patients from the 40 patients control group went to the reviews at 6 and 12 weeks. 108 patients completed the study.

No adverse effects were observed in any patient, neither in the treated group and the control group.

Table 2 and Figures 1-4 summarize the results.

Table 2. Evolution of patients at 6 and 12 weeks.

\begin{tabular}{|c|c|c|c|c|}
\hline & & Treated-group & Control group & Total \\
\hline \multicolumn{5}{|c|}{ Erythema } \\
\hline \multirow[t]{3}{*}{6 weeks } & No & $61(52.9 \%)$ & $14(43.8 \%)$ & 75 \\
\hline & Mild & 38 (36.9\%) & 11 (34.4\%) & 49 \\
\hline & Intense & 4 (3.9\%) & 7 (21.9\%) & 11 \\
\hline \multirow[t]{3}{*}{12 weeks } & No & 56 (73.7\%) & $16(50.0 \%)$ & 72 \\
\hline & Mild & 15 (19.7\%) & $9(28.1 \%)$ & 24 \\
\hline & Intense & $5(6.6 \%)$ & 7 (21.9\%) & 12 \\
\hline \multicolumn{5}{|c|}{ Dischromia } \\
\hline \multirow[t]{3}{*}{6 weeks } & No & 29 (28.2\%) & $10(31.3 \%)$ & 39 \\
\hline & Mild & 67 (65.2\%) & 18 (56.3\%) & 85 \\
\hline & Intense & 7 (6.8\%) & $4(12.5 \%)$ & 11 \\
\hline \multirow[t]{3}{*}{12 weeks } & No & 48 (63.2\%) & 7 (21.9\%) & 55 \\
\hline & Mild & 24 (31.6\%) & 22 (68.8\%) & 46 \\
\hline & Intense & $4(5.3 \%)$ & 3 (9.4\%) & 7 \\
\hline \multicolumn{5}{|c|}{ Atrophy } \\
\hline \multirow[t]{3}{*}{6 weeks } & No & $83(80.6 \%)$ & 23 (71.9\%) & 106 \\
\hline & Mild & $18(17.5 \%)$ & 7 (21.9\%) & 25 \\
\hline & Notorious & $2(1.9 \%)$ & 2 (6.3\%) & 4 \\
\hline \multirow[t]{3}{*}{12 weeks } & No & 65 (85.5\%) & 20 (62.5\%) & 85 \\
\hline & Mild & $9(11.8 \%)$ & $9(28.1 \%)$ & 18 \\
\hline & Notorious & $2(2.6 \%)$ & 3 (9.4\%) & 5 \\
\hline \multicolumn{5}{|c|}{ Hypertrophy } \\
\hline \multirow[t]{3}{*}{6 weeks } & No & 83 (80.6\%) & 26 (81.2\%) & 109 \\
\hline & Mild & $14(13.6 \%)$ & $4(12.5 \%)$ & 18 \\
\hline & Intense & $6(5.8 \%)$ & $2(6.2 \%)$ & 8 \\
\hline \multirow[t]{3}{*}{12 weeks } & No & 67 (89.3\%) & 25 (78.1\%) & 72 \\
\hline & Mild & 7 (9.4\%) & $6(18.8 \%)$ & 24 \\
\hline & Intense & $1(1.3 \%)$ & $1(3.1 \%)$ & 12 \\
\hline
\end{tabular}




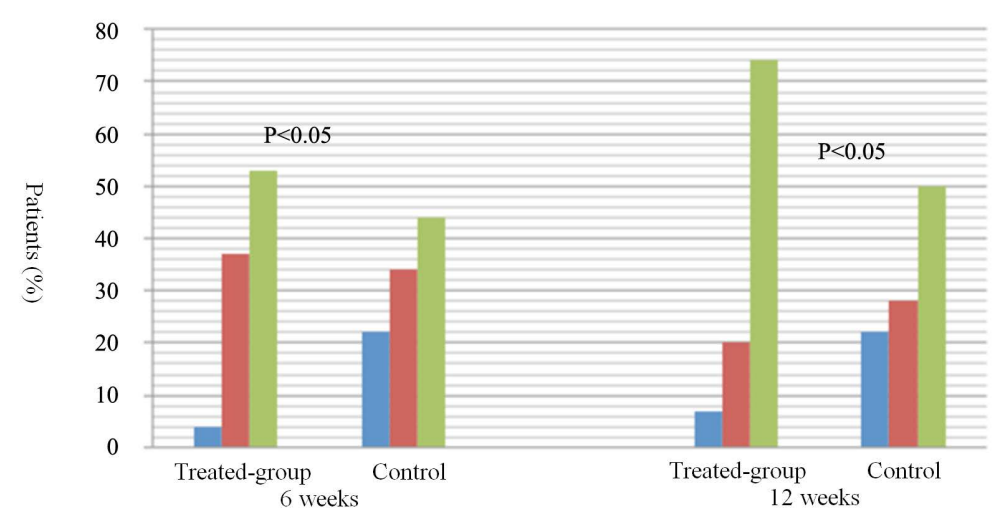

Figure 1. Subjective evaluation of erythema at 6 and 12 weeks. Blue bar, intense; red bar, mild; green bar, no erythema.

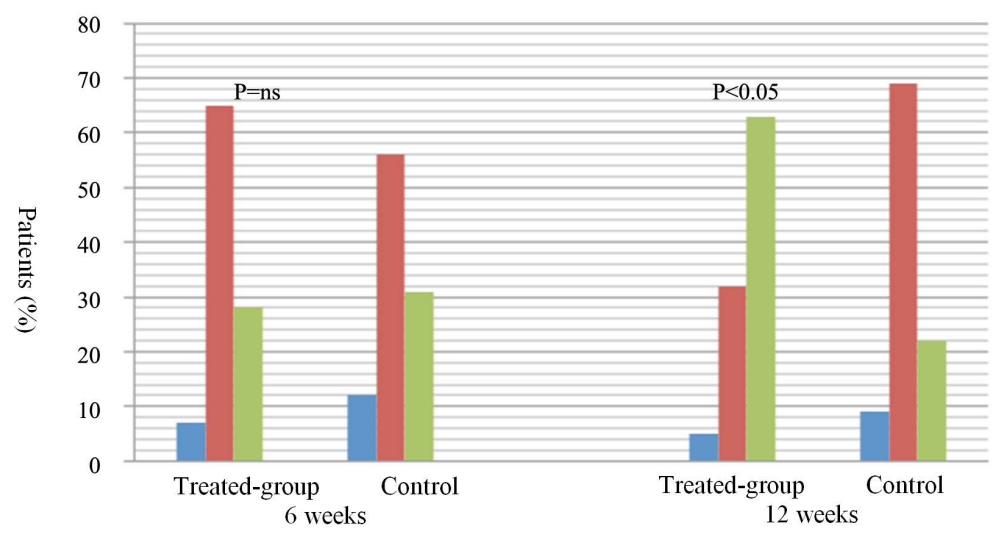

Figure 2. Subjective evaluation of discoloration at 6 and 12 weeks. Blue bar, intense; red bar, mild; green bar, no discoloration.

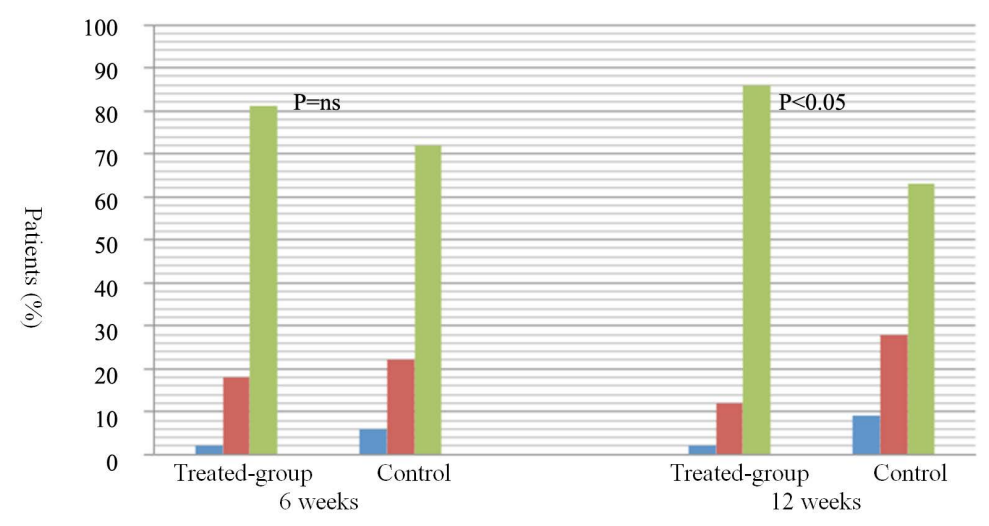

Figure 3. Subjective evaluation of atrophy at 6 and 12 weeks. Blue bar, notorious; red bar, mild; green bar, no atrophy.

In the subjective assessment of erythema carried out by the specialist (Figure 1), significant differences between the patients and the control group at both 6 and 12 weeks (73\% of treated patients did not presented erythema at 12 weeks vs. $50 \%$ of control patients) were founded.

Concerning the colorimetric changes taken together, a higher proportion of patients treated with RHO did not shown subjective discoloration at 6 and 12 weeks, although these differences were only significant at 12 weeks (63\% of treated patients without discoloration vs. 21\% control) (Figure 2). 


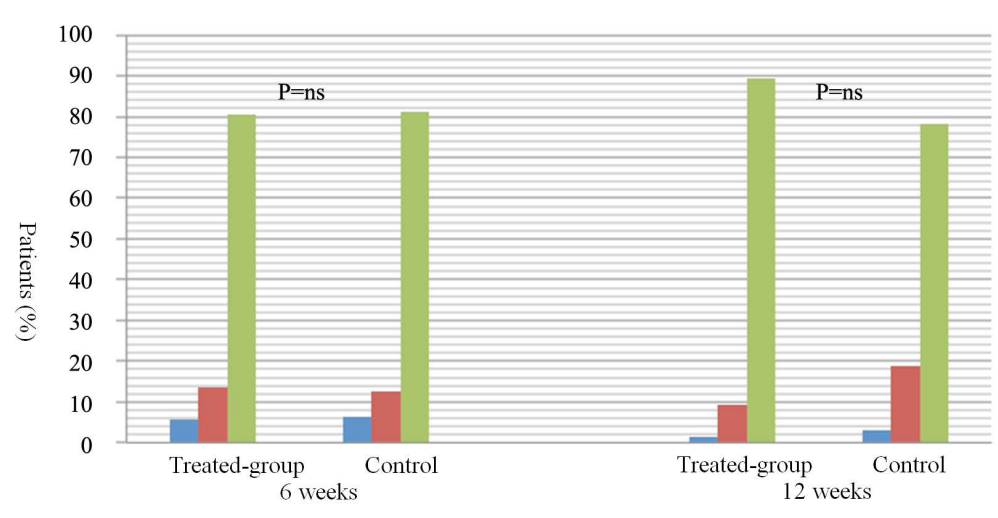

Figure 4. Subjective evaluation of hypertrophy at 6 and 12 weeks. Blue bar, notorious; red bar, mild; green bar, no hypertrophy.

The atrophy measurement (Figure 3) showed differences in patients treated with RHO at 6 and 12 weeks, with significant differences at the second examination (85\% vs. $62 \%$ of patients without atrophy found at 12 weeks).

Finally, hypertrophy analysis showed better evolution of scars on treated-group compared to control group at 6 and 12 weeks, but no statistically significant differences (Figure 4).

Figure 5 and Figure 6 show two examples of cutaneous scars treated with RHO, at the beginning of treatment (Figure 5(A) and Figure 6(A)) and after 12 weeks (Figure 5(B) and Figure 6(B)).

In daily dermatological practice, it is common that patients in whom a common surgical procedure is practiced not receive any topical treatment for cosmetic improvement after removal of sutures, beyond sunscreen always recommended. In this study, RHO showed a beneficial effect on clinical appearance of scars, in general, compared with those who were remained to their natural evolution. Our observations are concurrent with previous studies that evaluated the properties of RHO in healing injuries [11] [12].

Within the parameters analyzed, the most obvious improvement occurred in terms of erythema, with statistically significant differences in medical analysis at both 6 and 12 weeks in the RHO-treated-patients group (Figure 1). In the evolution of post-operative dyschromia, only significant differences at 12 weeks were found. It is possible that the scars color improvement may be associated with reduced inflammation [13] [14] and inhibition of chemotaxis [15] [16] that has been shown in in vitro and in vivo clinical trials using Rosehip seed oil.

A previous study used histological criteria to evaluate therapeutic properties of RHO [13], but we discard this possibility because the procedure was so invasive.

Several studies have found high levels of unsaturated fatty acids in RHO, mainly linoleic acid, linolenic acid and oleic acid [8] [9]. Essential fatty acids are basic components of the phospholipids in cell membranes, which are involved in numerous phosphorylation and cellular organization processes [10]. Some compounds like carotenoids and polyphenols have also been isolated from the RHO [17] [18], which are responsible for the antioxidant activity attributed to this compound. It is possible that the presence of these substances in the RHO contribute to a better evolution of the healing process, especially if it is applied early, as happened in our patients.

In the assessment of atrophy, a higher percentage of patients with outatrophy at 12 weeks, was found with significant differences, in the RHO-treated-group( $85 \%$ vs. $62 \%$ ). These differences may be related to the presence of derivatives of vitamin A (retinoic acid or naturally tretinoin) that have been previously identified in RHO [9]. Tretinoin topical treatment is widely used in dermatology, mainly in the context of acne vulgaris [19] and photo-induced skin damage [20], although previous references also exist about the benefit of its use in healing injury [21] [22].

With respect to the appearance of hypertrophy, no large differences were observed in treated patients, with similar percentages versus the control group. This observation is concurrent with the usual clinical experience, because, so far, no therapy has proven effective in a consistent way for the prevention or treatment of hypertrophic scars or keloids [23]. For now, early identification remains the mainstay for treatment.

\section{Conclusions}

As final conclusion, this study presented a group of patients in which the early application of RHO Repavar ${ }^{\circledR}$ in 


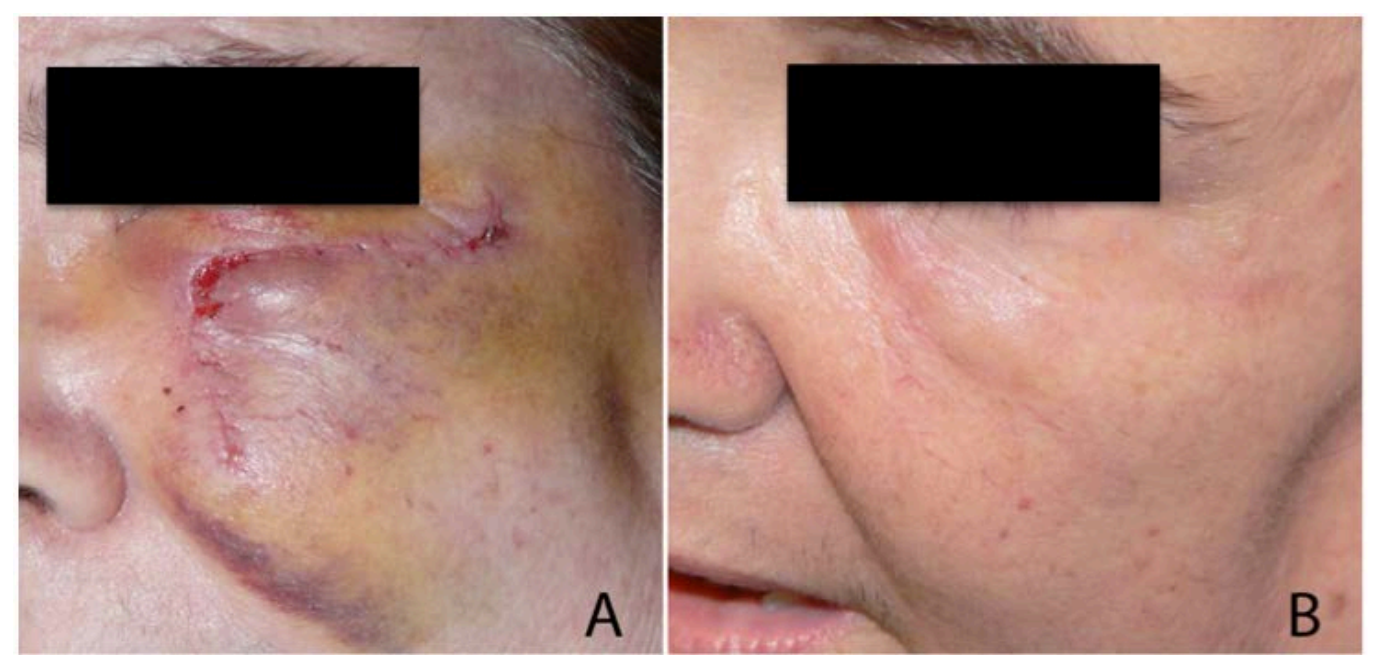

Figure 5. (A) Skin Scar on left side of the face after removal of sutures; (B) Clinical image after 12 weeks of treatment with RHO twice daily.

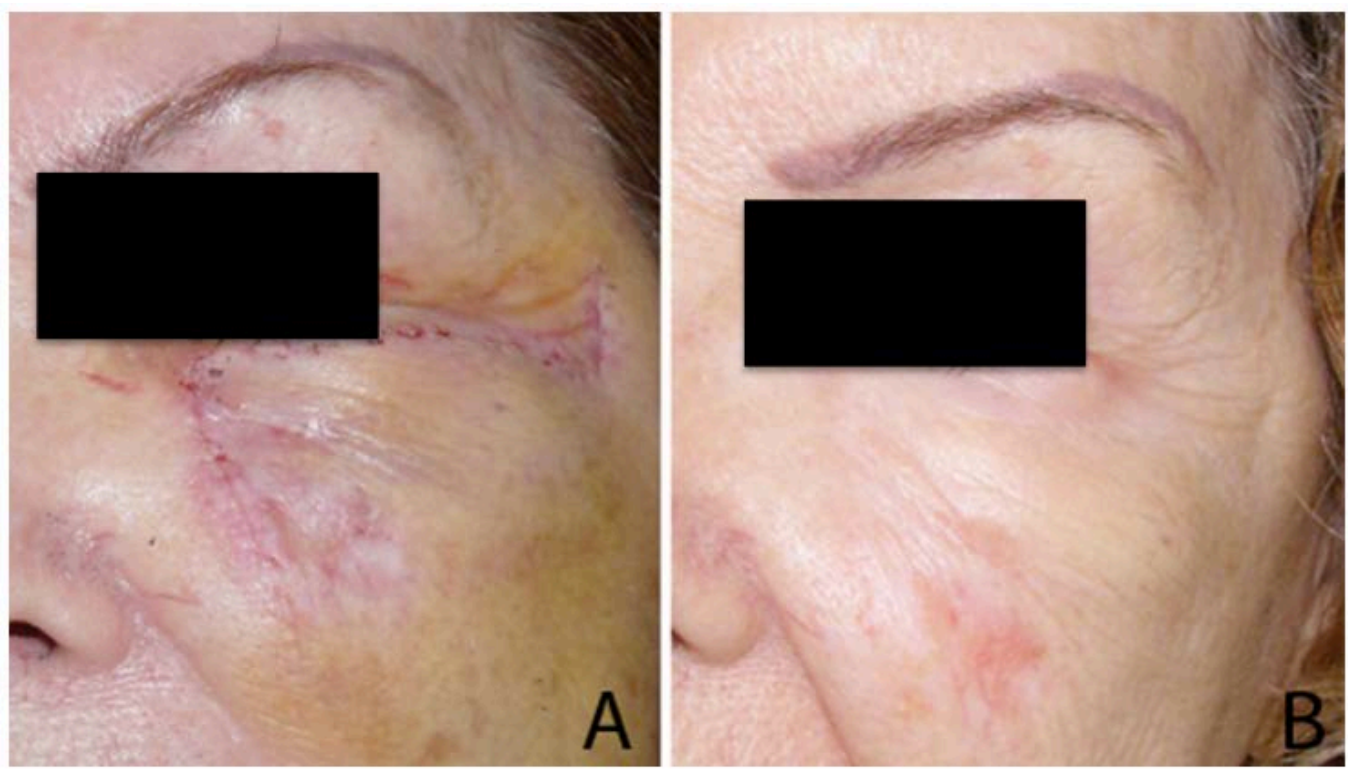

Figure 6. (A) Skin Scar on left side of the face after removal of sutures; (B) Clinical image after 12 weeks of treatment with AHM twice daily.

post-surgical scars generally resulted in a cosmetic improvement thereof. This improvement was observed subjectively, especially at the level of erythema, with significant differences at 6 and 12 weeks, and discoloration and atrophy, with significant differences at 12 weeks.

This study provides preliminary results that can support the development of other trials providing a larger number of patients and longer follow-up.

\section{Acknowledgements}

This study was sponsored by Ferrer Internacional, SA.

\section{References}

[1] Stadelmann, W.K., Digenis, A.G. and Tobin, G.R. (1998) Physiology and Healing Dynamics of Chronic Cutaneous Wounds. American Journal of Surgery, 176, 26-38. http://dx.doi.org/10.1016/S0002-9610(98)00183-4 
[2] Iba, Y., Shibata, A., Kato, M. and Masukawa, T. (2004) Possible Involvement of Mast Cells in Collagen Remodeling in the Late Phase of Cutaneous Wound Healing in Mice. International Immunopharmacology, 4, 1873-1880. http://dx.doi.org/10.1016/j.intimp.2004.08.009

[3] Arndt, K.A. (2006) Scar Revision. Elsevier, Philadelphia.

[4] McGrath, M.H. (1990) Peptide Growth Factors and Wound Healing. Clinics in Plastic Surgery, 17, 421-432.

[5] Cohen, I.K., Diegelman, R.F. and Lindblad, W.J. (1992) Wound-Healing: Biochemical and Clinical Aspects. Annals of Surgery, 96, 114. http://dx.doi.org/10.1097/00006534-199211000-00034

[6] Mustoe, T.A., Cooter, R.D., Gold, M.H., Hobbs, F.D., Ramelet, A.A. and Shakespeare, P.G. (2002) International Clinical Recommendations on Scar Management. Plastic and Reconstructive Surgery, 110, 560-571. http://dx.doi.org/10.1097/00006534-200208000-00031

[7] Dogan, A. and Kazankaya, A. (2006) Properties of Hose Hip Species Grown in Lake Van Basin (Eastern Anatolia Region). Asian Journal of Plant Sciences, 5, 120-122. http://dx.doi.org/10.3923/ajps.2006.120.122

[8] Ozcan, M. (2002) Nutrient Composition of Rose (Rosa canina L.) Seed and Oils. Journal of Medicinal Food, 5, 137140. http://dx.doi.org/10.1089/10966200260398161

[9] Valladares, J., Palma, M., Sandoval, C. and Carvajal, F. (1986) Cream Hip Oil (Rosa aff. rubiginosa I.). Part I: Formulation, Preparation and Primary Application in Tissue Regeneration. Annals Real Acad Farm., 52, 597-612.

[10] Santos, J.S., Vieira, A.B. and Kamada, I. (2009) The Rosehip Not Open Wounds Treatment: A Review. Revista Brasileira de Enfermagem, 62, 457-462. http://dx.doi.org/10.1590/S0034-71672009000300020

[11] Moreno, J.C., Good, J., Navas, J. and Camacho, F. (1990) Treatment of Cutaneous Ulcers with Musk Rose Oil. Cutan Med Ibero Lat Am., 18, 63-66.

[12] Camacho, F., Moreno, J.C., Conejo-Mir, J. and Bueno, J. (1994) Treatment of Post-Surgical Scars and Pure Oil Rosehip Seed Defects. Cutan Med Ibero Lat Am., 22, 23-30.

[13] Marchini, F.B., Martins, D.M., Teves, D.C. and Simöes, M.J. (1988) Rosehip Oil Effect on the Healing of Open Wounds. Revista Paulista de Medicina, 106, 356.

[14] Hakansson, A., Stene, C., Milhaescu, A., Molin, G., Ahrné, S. and Thorlacius, H. (2006) Rose Hip and Lactobacillus plantarum DSM 9843 Reduces Ischemia/Reperfusion Injury in the Mouse Colon. Digestive Diseases and Sciences, 51, 2094-2101. http://dx.doi.org/10.1007/s10620-006-9170-9

[15] Daels-Rakotoarison, D.A., Gressier, B., Trotin, F., Brunet, C., Luyckx, M. and Dine, T. (2002) Effects of Rosa canina Fruit Extract on Neutrophil Respiratory Burst. Phytotherapy Research, 16, 157-161. http://dx.doi.org/10.1002/ptr.985

[16] Larsen, E., Kharazmi, A., Christensen, L.P. and Christensen, S.B. (2003) An Antiinflammatory Galactolipid from Rose Hip (Rosa canina) That Inhibits Chemotaxis of Peripheral Blood Neutrophils in Vitro Huma. Journal of Natural Products, 66, 994-995. http://dx.doi.org/10.1021/np0300636

[17] Robert, P., Carlsson, R.M., Romero, N. and Masson, L. (2003) Stability of Spray-Dried Encapsulated Carotenoid Pigments from Rosehip (Rosa rubiginosa) Oleoresin. Journal of the American Oil Chemists' Society, 80, 1115-1120. http://dx.doi.org/10.1007/s11746-003-0828-4

[18] Salminen, J.P., Karonen, M., Lempa, K., Liimatainen, J., Sinkkonen, J. and Lukkarinen, M. (2005) Characterisation of Proanthocyanidin Aglycones and Glycosides from Rose Hips by High-Performance Liquid Chromatography-Mass Spectrometry, and Their Rapid Quantification Together with Vitamin C. Journal of Chromatography A, 1077, 170-180. http://dx.doi.org/10.1016/j.chroma.2005.04.073

[19] Torok, H.M. and Pillai, R. (2011) Safety and Efficacy of Micronized Tretinoin Gel (0.05\%) in Treating Adolescent Acne. Journal of Drugs in Dermatology, 10, 647-652.

[20] Ting, W. (2010) Tretinoin for the Treatment of Photodamaged Skin. Cutis, 86, 47-52.

[21] Harris, D.W., Buckley, C.C., Ostlere, L.S. and Rustin, M.H. (1991) Topical Retinoic Acid in the Treatment of Acne Scarring Fine. British Journal of Dermatology, 125, 81-82. http://dx.doi.org/10.1111/j.1365-2133.1991.tb06048.x

[22] de Limpens A.M., J. (1980) The Local Treatment of Hypertrophic Scars and Keloids with Topical Retinoic Acid. British Journal of Dermatology, 103, 319-323. http://dx.doi.org/10.1111/j.1365-2133.1980.tb07251.x

[23] Berman, B., Villa, A.M. and Ramirez, C.C. (2004) Novel Opportunities in the Treatment and Prevention of Scarring. Journal of Cutaneous Medicine and Surgery, 8, 32-36. http://dx.doi.org/10.1007/s10227-004-0806-0 